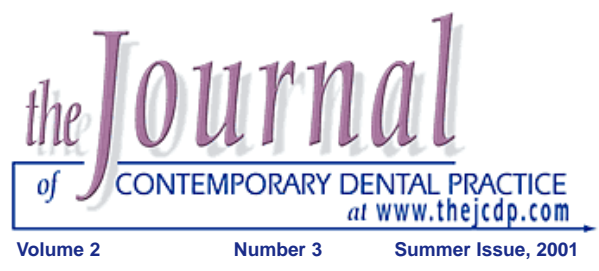

\title{
Obsessive Compulsive Disorder: \\ A Case Report
}

\section{Chris Herren, DMD; John Lindroth, DDS}

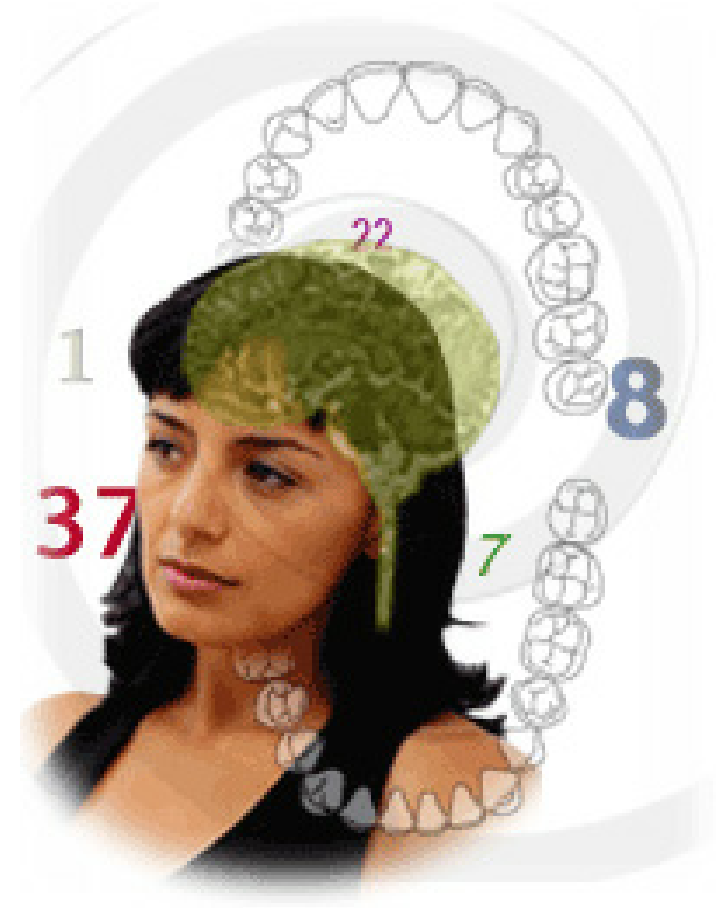

Abstract

A general dentist often will find the most challenging aspect of dentistry is patient management. In the controlled environment of a dental school, many students are not exposed to certain patient populations. It is likely that their first experience with particular patient pools will be in private practice. One such group of patients is those suffering from Obsessive Compulsive Disorder (OCD). This article reviews the clinical signs and symptoms of this group of patients.

Keywords: Obsessive Compulsive Disorder, OCD

Citation: Herren C, Lindroth J. Obsessive Compulsive Disorder. J Contemp Dent Pract 2001;(2)3: 041-049. 


\section{Introduction}

A 30-year old female presents to a dental office for an initial evaluation. Her medical history was unremarkable, and she was in very good dental health. A clinical and radiographic examination was performed revealing no periodontal probing depths greater than $3 \mathrm{~mm}$, and there was no evidence of dental caries. Moderate to severe wear on teeth \# 21, 22, 27, and 28 was noted. The patient initially denied any parafunctional habits.

She was informed about the wear on her teeth and counseled on bruxism.

Upon her return for a six-month examination, the health history review revealed that her physician had made a diagnosis of Obsessive Compulsive Disorder (OCD). The patient recounted a history of being imprisoned by a bizarre set of rituals, one of which was tapping and clicking her teeth. If she did not tap her teeth 8 times prior to answering a question on an exam she feared missing the question. Also, when driving a car prior to changing lanes she would tap her teeth twice. The consequences of not performing these rituals would change daily. Her most often cited consequence was harm to a family member or loved one. A decision to delay elective restorative treatment was agreed upon with the patient. After several months of drug and behavioral therapy with her physician, the patient returned to complete her dental treatment.

\section{Discussion}

OCD strikes 1 in 50 people during their lifetime. ${ }^{1}$ It occurs with equal frequency in men and women and research suggests that OCD has familial tendencies. ${ }^{2}$ The illness commonly presents with multiple obsessions and compulsions. ${ }^{1}$ Typically people suffering from OCD experience unwanted thoughts and habits, and they characteristically perform bizarre rituals. ${ }^{2}$ They feel that bad things will happen to them or their family members if these rituals are not carried out in an exact manner. ${ }^{2}$ In its less severe form, OCD is an illness that wastes the patient's time and often interferes with their quality of life. In the most severe form, this disorder can be very debilitating to both the patient and their family.
Comorbidity is common with OCD, coexisting with other disorders such as anxiety disorders, affective disorders, and substance abuse. ${ }^{1,3}$ The diagnosis of OCD is specific and should not be made until other psychiatric disorders have been ruled out. The symptoms should be isolated to be sure they are not manifestations of other disorders such as major depression, mania, schizophrenia, eating disorders, or preoccupation with food. ${ }^{4}$ For example, a comorbid depression can result from the fatigue and anxiety associated with trying to keep up with the constant demands the OCD presents. $^{3}$

OCD has two components as the name implies. The "obsessive" component manifests as recurrent thoughts, ideas, or images that are a disruptive force in the sufferer's life. These obsessions are involuntary and result in the "compulsive" part of the disorder., ${ }^{1,14}$ The compulsions are then played out in response to the obsessions in an attempt to relieve the subsequent mounting anxiety. Patients may be aware they are performing these rituals but are unable to stop themselves from following through with the associated compulsion.

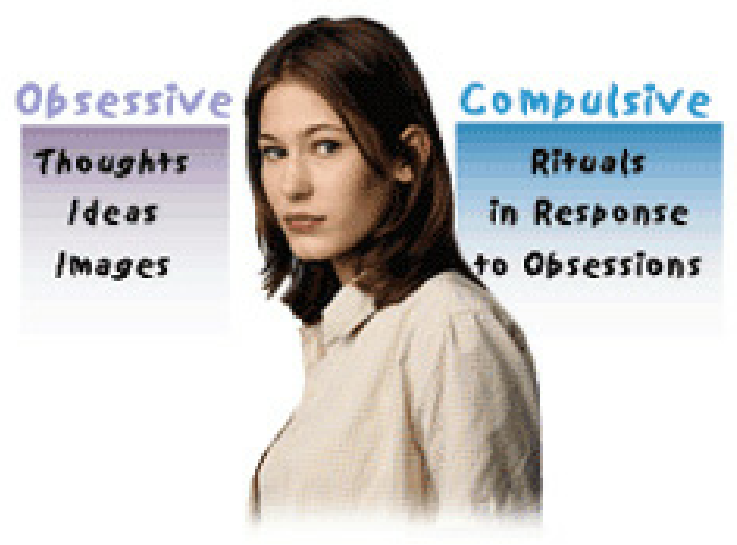

There may be several different subtypes of etiologies for the development of OCD. ${ }^{9}$ The pathophysiology of OCD is a dysfunction in corticospinal pathways of the central nervous system. ${ }^{10,11}$ Research has shown that OCD is associated with deficient amounts of the neurotransmitter, serotonin, in the basal ganglion and communicating regions of the subcortical structures. $^{5,12}$ (Figure A) As a result, synaptic dysfunction in the cortical inhibitory and excitatory mechanism occurs, leading to the obsessivecompulsive behaviors. Other research has supported the finding of basal ganglion involvement in some children associated with an autoimmune response to streptococcal infection. ${ }^{6}$ 


\section{Figure A}

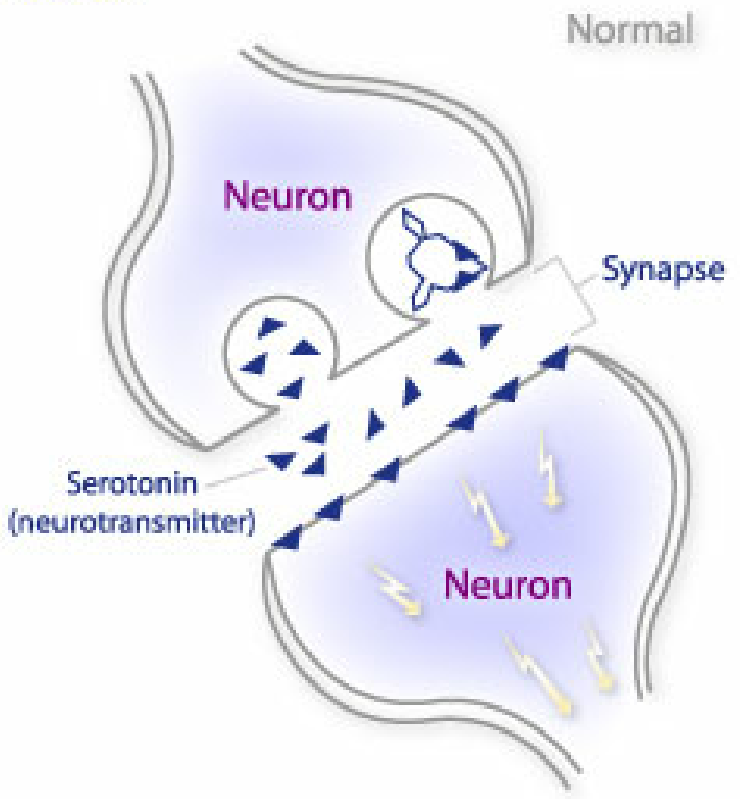

\section{Adequate Levels of serotonin for normal neronal firing}

Dentists should be aware of the signs, symptoms, and clinical treatment of OCD so proper dental management can be followed. Many patients may be reluctant to talk about the specifics of their problem. A thorough discussion of the disorder and a consultation with the patient's physician is prudent in cases where complex dental treatment is required.

\section{Signs and Symptoms}

Patients with OCD may or may not have outward manifestations of this disorder. ${ }^{1-4}$ By definition, OCD patients have obsessions that cause them to perform certainacts or rituals compulsively.

(Table 1$)^{2}$ These compulsions can manifest in a verbal, subvocal, or physical manner. A commonality found in all OCD patients is an obsessive-compulsive behavior with numbers. Most patients have an obsession with performing their compulsions a certain number of times. ${ }^{2}$ The act of taking an obsession to the next level and acting on that obsession is where the patient's therapist attempts to break the cycle of this mal-behavior. Frequently patients suffer from depression in addition to OCD. Often patients are successfully treated with behavior modification directed by a therapist.

In more severe cases, drug therapy in combination with behavior modification is needed. Drug therapy (Table 2) is most often accomplished with selective serotonin reuptake inhibitors (SSRI's). ${ }^{7,8}$ (Figure B)

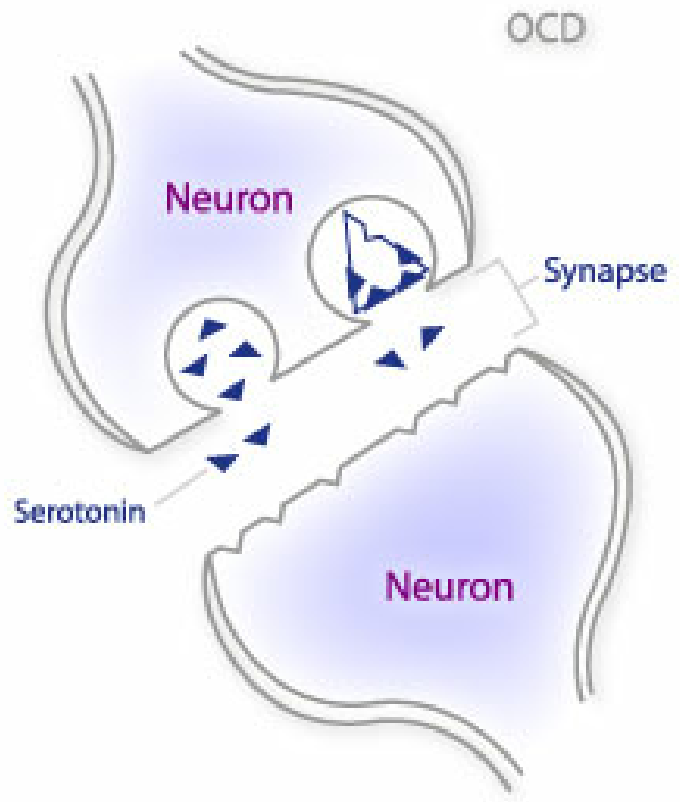

Synaptic dysfunction from deficient amounts of serotonin causing decreased neuronal firing.

Neuroimaging studies have shown a change in brain function following SSRI therapy. ${ }^{13}$ SSRI's have associated side effects. The side effect most pertinent to dentistry is xerostomia. ${ }^{14}$ Patients with xerostomia may need to have a shorter recall interval and must maintain excellent oral hygiene. Fluoride rinses and gels, as well as intraoral moistening agents may be prescribed for caries management. As always, before prescribing any medications in the course of dentistry, a screening for drug interactions must be performed to preclude any untoward effects with SSRI's.

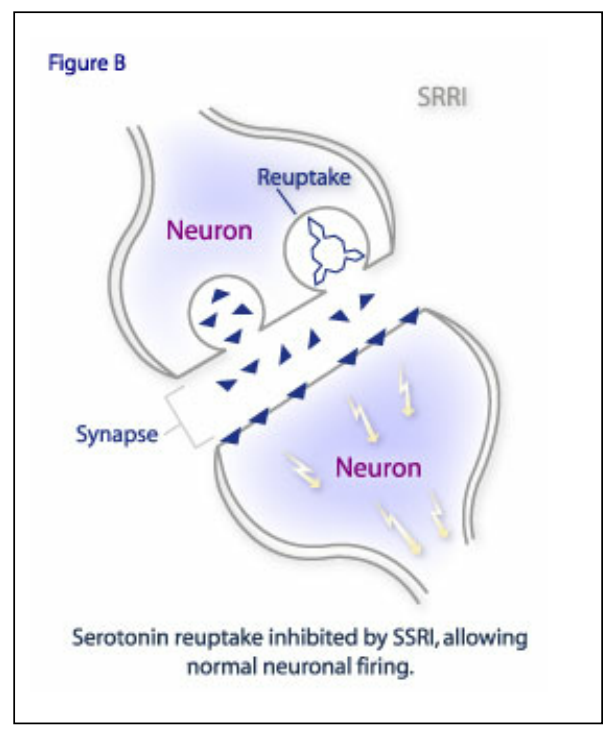

3

The Journal of Contemporary Dental Practice, Volume 2, No. 3, Summer Issue, 2001 
Table 1. Examples of Signs and Symptoms

\section{Obsessions}

\begin{tabular}{|l|l|}
\hline Germs, contamination & Fears of contracting an illness. Fear or revulsion of body waste. \\
\hline Obsessions with aggresive content & Fear of harming others or self. Violent thoughts \\
\hline Sexual images & Sexual thoughts that are considered inappropriate. \\
\hline Religious obsessions & Sacrilegious images and Blasphemous thoughts \\
\hline Need for symmetry & A need to align objects. Obsessed about neatness \\
\hline Hoarding & Saving trash, newspapers and other items. \\
\hline Nonsensical doubts & Fear that one has failed to do something. \\
\hline Repetitive rituals & Repeating phrases, words, or routines. \\
\hline Superstitions & Example: believe certain numbers are lucky \\
\hline Compulsion & Repeatedly wash, fear of touching objects \\
\hline Cleaning and washing & Counting, repeatedly performing acts Repeated arranging of items \\
\hline Checking compulsions & Accumulating worthless objects \\
\hline Hoarding & Symmetry, Need to keep doing projects over \\
\hline Having things just right & $\begin{array}{l}\text { Need to tap or touch certain objects } \\
\text { Mental rituals: Counting ritual, Repeated praying, Excessive list } \\
\text { making, Blinking or staring rituals }\end{array}$ \\
\hline Miscellaneous &
\end{tabular}

\begin{tabular}{|l|l|l|}
\hline \multicolumn{3}{|c|}{ Table 2. Common 0CD Drugs } \\
\hline & & Recommended dose \\
\hline Fluvoxamine & Luvox & $100 \mathrm{mg}-300 \mathrm{mg} / \mathrm{day}$ \\
\hline Paroxetine & Paxil & $40 \mathrm{mg} / \mathrm{day}$ \\
\hline Sertraline & Zoloft & $25 \mathrm{mg}-200 \mathrm{mg} / \mathrm{day}$ \\
\hline Fluoxetine & Prozac & $20 \mathrm{mg}-60 \mathrm{mg} / \mathrm{day}$ \\
\hline
\end{tabular}




\section{Summary}

The objective of the general dentist is to provide quality patient care. To achieve this end, a dentist treating a patient with OCD must understand the disorder and be able to manage the patient effectively. The treatment plan and management of patients can often be the most complex part of dentistry. A simple restorative case that can become a challenge with OCD patients can also be well managed with knowledge and preparation.
The American Psychiatric Association (APA) web site (http://www.psych.org) is an excellent source for obtaining more information about OCD. The mailing address forthe APA is:

\author{
American Psychiatric Association \\ 1400 K Street NW \\ Washington, DC 20005 \\ (888) 357-7924 \\ FAX 202-682-6850
}

\section{References}

1. Karno MA, Golding JM, Sorenson SB, et. al. The Epidemiology of Obsessive-Compulsive Disorder: Implications for a serotonergic theory. Am J Psychiatry. 1988;147: 1209-1215.

2. Schwartz MD. Brain Lock (1996) Regan Books. New York, New York.xiii-xviii

3. Jenike MA, Baer L, Minicheiello WE. Obsessive Compulsive Disorders-Practical Management (3rd ed.). Chicago: Mosby.

4. Karno M, Golding JM, Sorenson SB, Burnam MA.. The epidemiology of obsessive-compulsive disorder in five US communities. Arch Gen Psychiatry. 1988 Dec;45(12):1094-9.

5. Jenike MA. An update on obsessive-compulsive disorder. Bull Menninger Clin. 2001 Winter;65(1):4-25. Review.

6. Greenberg BD, Ziemann U, Cora-Locatelli G, Harmon A, Murphy DL, Keel JC, Wassermann EM. Altered cortical excitability in obsessive-compulsive disorder. Neurology. 2000 Jan 11;54(1):142-7.

7. Giedd JN, Rapoport JL, Garvey MA, Perlmutter S, Swedo SE. MRI assessment of children with obsessive-compulsive disorder or tics associated with streptococcal infection. Am J Psychiatry. 2000 Feb;157(2):281-3.

8. Dolberg OT, lancu I, Sasson Y, Zohar J. The pathogenesis and treatment of obsessive-compulsive disorder. Clin Neuropharmacol. 1996 Apr;19(2):129-47. Review.

9. Greist JH. An integrated approach to treatment of obsessive compulsive disorder. J Clin Psychiatry. 1992 Apr;53 Suppl:38-41. Review.

10. Pauls DL, Leckman JF. The inheritance of Gilles de la Tourette's syndrome and associated behav iors. Evidence for autosomal dominant transmission. N Engl J Med. 1986 Oct 16;315 (16):993-7.

11. Rauch SL, Jenike MA. Neurobiological models of obsessive-compulsive disorder. Psychosomatics. 1993 Jan-Feb;34(1):20-32. Review.

12. Rauch SL, Jenike MA. Neural mechanisms of obsessive compulsive disorder Current review of Mood and Anxiety Disorders 1997;1:84-89.

13. Barr LC, Goodman WK, Price LH, McDougle CJ, Charney DS. The serotonin hypothesis of obsessive compulsive disorder: implications of pharmacologic challenge studies. J Clin Psychiatry. 1992 Apr;53 Suppl:17-28. Review.

14. Rauch SL, Jenike MA, Alpert NM, Baer L, Breiter HC, Savage CR, Fischman AJ. Regional cerebral blood flow measured during symptom provocation in obsessive-compulsive disorder using oxygen 15-labeled carbon dioxide and positron emission tomography. Arch Gen Psychiatry. 1994 Jan;51(1):62-70.

15. Wynn R. Drug Information Handbook for Dentistry 1997-1998. Lexi-Comp Incorporated. Hudson, Ohio. 


\section{Chris Herren, DMD}
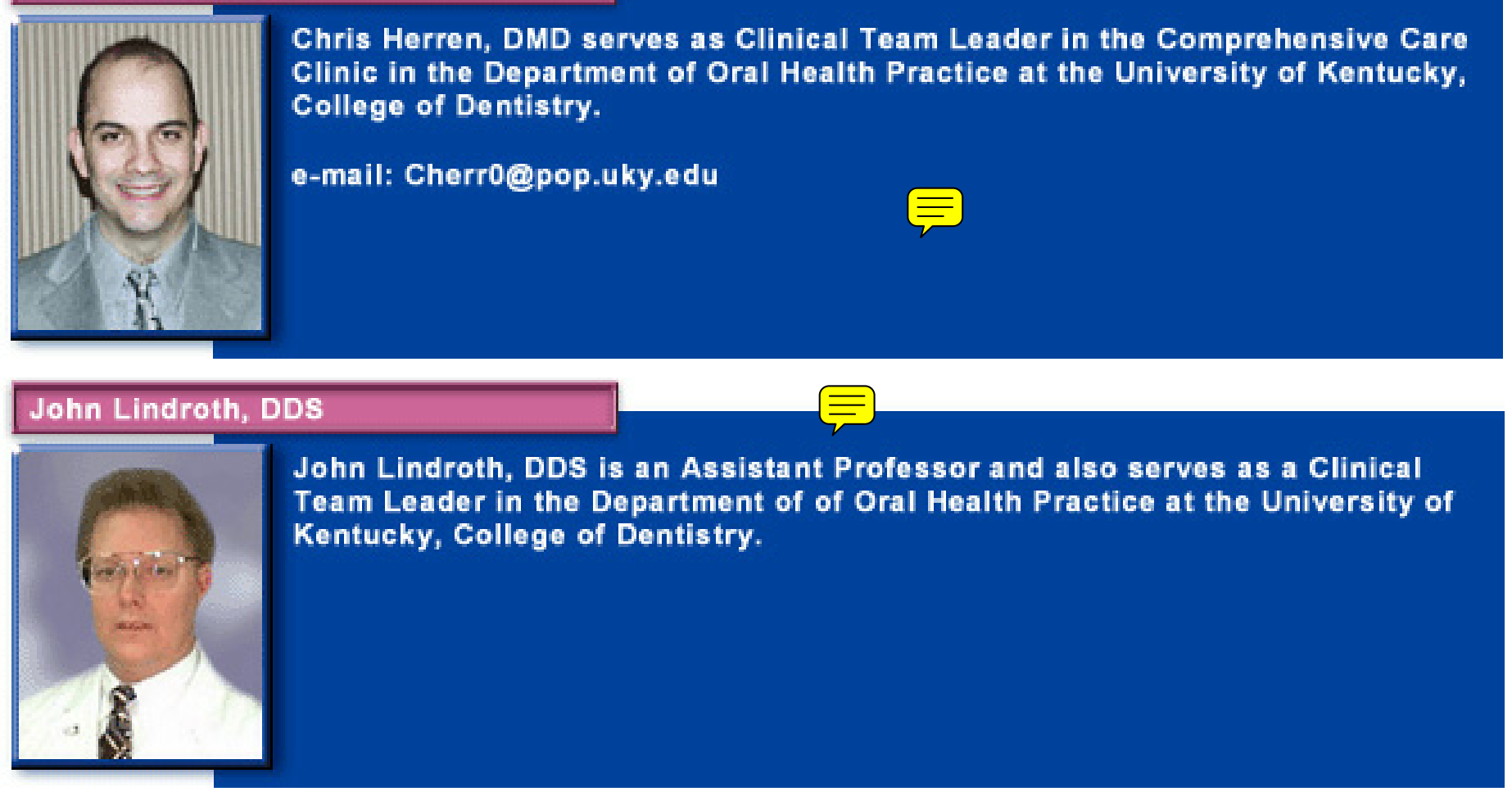